\title{
Clinical significance of vascular endothelial growth factor in hepatitis $C$ related hepatocellular carcinoma in Egyptian patients
}

This article was published in the following Dove Press journal:

Journal of Hepatocellular Carcinoma

14 June 2016

Number of times this article has been viewed

Mohamed Magdi El-Sadek

Ali Atta ${ }^{1,2}$

Hazem Mahmoud Atta ${ }^{3,4}$

Magdy Abdel-Mawgoud Gad ${ }^{2}$

Laila Ahmad Rashed ${ }^{4}$

Ebada M Said ${ }^{2}$

Sharaf El-Sayed Ali

Hassanien ${ }^{2}$

Ahmed O Kaseb 5

'Department of Medicine, Rabigh

Faculty of Medicine, King Abdulaziz

University, Jeddah, Kingdom of Saudi

Arabia; ${ }^{2}$ Department of Hepatology,

Gastroenterology and Infectious

Diseases, Faculty of Medicine, Benha

University, Benha, Egypt; ${ }^{3}$ Department

of Clinical Biochemistry, Rabigh

Faculty of Medicine, King Abdulaziz

University, Jeddah, Kingdom of Saudi

Arabia; ${ }^{4}$ Department of Medical

Biochemistry and Molecular Biology,

Faculty of Medicine, Cairo University,

Cairo, Egypt; ${ }^{5}$ Department of

Gastrointestinal Medical Oncology,

The University of Texas MD Anderson

Cancer Center, Houston, TX, USA
Background and aims: Several angiogenic factors are involved in the development and progression of hepatocellular carcinoma (HCC), a hypervascular tumor. Vascular endothelial growth factor (VEGF) is a primary driving force for angiogenesis, and its overexpression has been reported in HCC. However, the significance of plasma and tissue VEGF levels in HCC in Egyptian patients with chronic hepatitis $\mathrm{C}(\mathrm{CHC})$ infection is understudied. The aim of this study was to evaluate the role of VEGF (measured in plasma and liver tissue) in patients with hepatitis $\mathrm{C}$ virus-related HCC and to assess its significance in the diagnosis and prognosis of HCC.

Materials and methods: A total of 90 subjects were studied. Among 90 subjects, 60 with $\mathrm{CHC}$ were examined and were subdivided into two groups: 30 patients with $\mathrm{CHC}$-related HCC (HCC group) and 30 patients with $\mathrm{CHC}$ without HCC (non-HCC group). Thirty apparently healthy subjects served as the control group. VEGF was estimated in plasma by enzyme-linked immunosorbent assay and its expression in liver tissue was evaluated by real-time polymerase chain reaction. VEGF expression level and its relationship to tumor parameters, patients' liver function profile, and patients' clinical parameters were also investigated.

Results: Plasma VEGF levels in the HCC group were significantly higher than those of the non-HCC group, and both groups had significantly higher plasma VEGF levels than did the control group. Liver tissue VEGF expression was significantly higher in the HCC group than in the non-HCC group and positively correlated with plasma VEGF in the HCC group. The plasma VEGF levels were positively correlated with patients' age, aspartate aminotransferase levels, serum alpha-fetoprotein levels, the presence of portal vein thrombosis, and the number of hepatic focal lesions in the HCC group. However, plasma VEGF levels were not significantly correlated with the Child-Pugh score, alanine aminotransferase levels, the size of focal lesions, and Okuda stage. Using both the VEGF and alpha-fetoprotein levels to detect HCC maximizes the sensitivity and specificity.

Conclusion: Plasma levels of VEGF may be a useful diagnostic and prognostic marker for $\mathrm{HCC}$ in patients who have been diagnosed with $\mathrm{CHC}$.

Keywords: VEGF, hepatocellular carcinoma, hepatitis $\mathrm{C}$ virus

\section{Introduction}

Hepatocellular carcinoma (HCC) is the fifth most common neoplasm in men, seventh in women, and third highest cause of cancer-related deaths worldwide, ${ }^{1}$ with 6 million new cases diagnosed annually and approximately 600,000 deaths every year. ${ }^{1,2}$ HCC is multifactorial in etiology and complex in the pathogenesis ${ }^{3}$ and usually develops in patients diagnosed with liver cirrhosis. ${ }^{4}$

Egypt has the highest hepatitis $\mathrm{C}$ virus (HCV) prevalence worldwide, and chronic hepatitis $\mathrm{C}(\mathrm{CHC})$ is a major risk factor for the development of $\mathrm{HCC},{ }^{5}$ which is the second most common malignant tumor in both sexes. ${ }^{6}$

\footnotetext{
Correspondence: Mohamed Magdi

El-Sadek Ali Atta

Department of Hepatology,

Gastroenterology and Infectious Diseases, Faculty of Medicine, Benha University,

52 Taawon Street, Ahram Road,

Giza 1215।, Egypt

Tel +20 I00 5370605

Fax $+2096654 \mid 264352$

Email magdielsadek@yahoo.co.uk
} 
Angiogenesis is believed to play a major role in the development and progression of HCC, a hypervascular tumor. ${ }^{7,8}$ Angiogenesis is a very complicated process regulated by many angiogenic factors, including vascular endothelial growth factor (VEGF). ${ }^{9}$ VEGF is one of the most important angiogenesis regulators and has been suggested as a useful biological marker of tumor invasiveness and prognosis in HCC. ${ }^{10,11}$ VEGF is the most potent angiogenic factor that promotes endothelial proliferation and increases vascular permeability by binding to specific receptors in endothelial cells. ${ }^{12}$ Because the majority of HCC cases develop in cirrhotic livers, HCC surveillance with alpha-fetoprotein (AFP) and ultrasonography (US) has been recommended for persons with cirrhosis; however, the AFP level is insensitive for early diagnosis of the disease. ${ }^{13}$ As early detection of HCC is essential ${ }^{14}$ new serologic markers with sufficient sensitivity and specificity are needed.

The aim of this study was to evaluate the role of VEGF (measured in plasma and liver tissue) in patients with HCVrelated $\mathrm{HCC}$ and to assess its significance in the diagnosis and prognosis of $\mathrm{HCC}$.

To our knowledge, this is the first study testing VEGF in both plasma and liver tissue in Egyptian patients with HCV where the prevalent genotype is genotype 4 .

\section{Methods}

\section{Patients}

This study included 90 Egyptian participants and was conducted at the Department of Hepatology, Gastroenterology, and Infectious Diseases at Benha University Hospital, Egypt, from November 2011 to December 2013. The study was approved by the ethical committee of Benha Faculty of Medicine. The patients provided written informed consent.

Sixty patients with $\mathrm{CHC}$ were subdivided into two groups: 30 patients with HCV-related HCC (HCC group) and 30 patients who had CHC but not HCC (non-HCC group). The HCC group was subdivided into HCC1, which included 15 patients with a compensated liver profile (Child-Pugh class A) ${ }^{15}$ and HCC2, which included 15 patients with $\mathrm{HCC}$ and decompensated cirrhosis (ChildPugh class B and C). The non-HCC group was subdivided into non-HCC1, which included 15 patients with CHC (metaanalysis of histological data in viral hepatitis [METAVIR] $\mathrm{F}<4)^{16}$ and non-HCC2, which included 15 patients with (Child-Pugh class B and C) post-HCV cirrhosis. The control group included 30 apparently healthy subjects with matching age and sex to the study groups. The control group showed a normal liver profile and tested negative for hepatitis B and C viral markers.
Patients who refused to give consent and, also, patients with chronic liver disease of causes other than chronic $\mathrm{HCV}$ infection (including coinfection with hepatitis B virus) were excluded.

The 60 patients gave a full and detailed medical history and underwent a complete clinical examination, routine laboratory tests with emphasis on liver and kidney profiles, viral B and $\mathrm{C}$ markers, abdominal US and Doppler US and triphasic computed tomography (CT), plasma VEGF levels, in addition to US-guided liver biopsy for $\mathrm{HCC} 1$ and non-HCC1 groups. The 30 controls were subjected to clinical, routine laboratory tests, viral $\mathrm{B}$ and $\mathrm{C}$ markers and plasma VEGF.

$\mathrm{HCC}$ was diagnosed using clinical criteria and the findings obtained by B-mode US and CT.

\section{Biochemical studies}

Blood samples were collected from all 90 participants in the morning in plasma separator tubes and were centrifuged at $3,000 \times g$ for 15 minutes followed by plasma separation; plasma was then stored at $-80^{\circ} \mathrm{C}$. At the time of analysis, all reagents and samples were allowed to reach room temperature, and all samples, standards, and controls were assayed. An investigator blinded to the clinical data quantitatively measured plasma VEGF concentrations using an enzymelinked immunosorbent assay kit (Quantikine Human VEGF Immunoassay; R\&D Systems, Inc., Minneapolis, MN, USA), according to the manufacturer's instructions. US-guided liver biopsy was performed in the Department of Hepatology, Gastroenterology, and Infectious Diseases at Benha University Hospital. Physicians used a tru-cut needle (16-gauge) for patients who had no contraindications or expected risks for this procedure. Liver biopsies were taken from the hepatic focal lesion before tumor ablation in all patients in the $\mathrm{HCC} 1$ group and from liver tissue in all patients in the non-HCC1 group. Liver tissue samples were stored at $-80^{\circ} \mathrm{C}$ until realtime quantitative reverse transcription polymerase chain reaction (PCR) was performed to measure the VEGF levels via liver expression of VEGF-165 mRNA.

\section{Detection of VEGF gene expression by real-time PCR Extraction of RNA from liver biopsy}

Total RNA was extracted from liver tissue biopsy using SV Total RNA Isolation system (Promega Corporation, Fitchburg, WI, USA). The yield of total RNA obtained was determined spectrophotometrically at $260 \mathrm{~nm}$. The extracted RNA was reverse transcribed into cDNA using Real-time Polymerase Chain Reaction (RT-PCR) kit (Stratagene, La Jolla, CA, USA). 


\section{qPCR}

The VEGF gene-specific forward and reverse primer pair was normalized. Each primer (forward and reverse) concentration in the mixture was $5 \mathrm{pmol} / \mu \mathrm{L}$. The forward VEGF primer was: 5'-ATGAACTTTCTGCTGTCTTGG-3'. The reverse VEGF primer was: $5^{\prime}$-TCACCGCCTCGGCTTGTCACA-3'. PCR conditions were as follows: at $92^{\circ} \mathrm{C}$ for 2 minutes. $55^{\circ} \mathrm{C}$ for 30 seconds, $72^{\circ} \mathrm{C}$ for 30 seconds ( 30 cycles), $92^{\circ} \mathrm{C}$ for 2 minutes, $55^{\circ} \mathrm{C}$ for 30 seconds, and $72^{\circ} \mathrm{C}$ for 5 minutes. The instrument used was ABI Prism 7900HT Fast Real Time PCR system (Applied Biosystems, Foster City, CA, USA). At the end of a quantitative $\mathrm{PCR}$ run, the relative quantification was used to assess the results.

\section{Statistical analysis}

Statistical analysis was performed using the Statistical Package for the Social Sciences (SPSS version 11.0; SPSS, Chicago, IL, USA). Quantitative variables were summarized using means and standard deviation (SD). Qualitative data were summarized using frequencies and percentage. Unpaired Student's $t$-tests (two-sided) were used to test the significance of difference between the mean value of the two studied groups, and the chi-square test was used to compare categorical variables. Pearson's correlation test was used when indicated. $P$-values $\leq 0.05$ were considered statistically significant.

\section{Results}

Plasma VEGF levels were significantly higher in the HCC group $(488.46 \pm 139.07 \mathrm{pg} / \mathrm{mL})$ than in the non-HCC group $(197.93 \pm 50.37 \mathrm{pg} / \mathrm{mL})$, and both groups had significantly higher plasma VEGF levels compared to the control group $(134.13 \pm 51.94 \mathrm{pg} / \mathrm{mL})(P \leq 0.001)$. Liver tissue VEGF levels were significantly higher in the HCC group (1.92 \pm 0.6$)$ as compared to the non-HCC group $(0.62 \pm 0.28)$ (Table 1$)$. This number represents the results normalized in relation to those of the housekeeping gene (beta-actin).

The plasma VEGF levels were significantly correlated with the age of patients, the number of HCC focal lesions, portal vein thrombosis, and the aspartate aminotransferase and serum AFP levels. Plasma VEGF levels were not significantly correlated with the maximum size of the tumors. They were not significantly correlated with Child-Pugh class or Model for End-Stage Liver Disease (MELD) score. ${ }^{17}$ Moreover, plasma VEGF levels were not correlated with serum albumin, alanine aminotransferase (ALT) levels, serum bilirubin, or international normalized ratio (INR) among HCC groups (Table 2). In addition, plasma VEGF levels were not correlated with Okuda stage $(r=-0.057, P$-value $=0.764)$.

Liver tissue VEGF expression levels were significantly related to patients' age, plasma VEGF levels, and MELD score; however, liver tissue VEGF expression levels were not significantly correlated with the Okuda stage or AFP level (Table 3).

We assessed plasma VEGF levels at different cutoff values. At a cutoff value of $271.85 \mathrm{pg} / \mathrm{mL}$, both the sensitivity and specificity for detecting HCC were $90 \%$, with an area under the receiver operating characteristic curve (AUROC) of 0.972 (Figure 1). Using both plasma VEGF and serum AFP levels increased the sensitivity and specificity for detecting HCC to $100 \%$ and $98.7 \%$, respectively (AUROC $=0.99)$

\section{Discussion}

In this study, the mean plasma VEGF level in the HCC group $(488.46 \mathrm{pg} / \mathrm{mL})$ was significantly higher than that of the non-HCC group (197.39 $\mathrm{pg} / \mathrm{mL})$, and both groups had a significantly higher median plasma VEGF level compared to the control group (134.13 pg/mL). This significant elevation was expected, since angiogenesis is critical for both the development and progression of HCC. The finding that VEGF is overexpressed in the non-HCC patients might be explained by the assumption that activation of VEGF precedes the appearance of hepatic neoplasia. This finding agrees with El-mezayen and Darwish. ${ }^{18}$ Also, this finding supports Mukozu et al ${ }^{19}$ work which concluded that the serum VEGF level was significantly higher in HCC patients than in non-HCC patients. However, it reported no significant difference in plasma VEGF levels between the control group and the non-HCC group. ${ }^{19}$ Similarly, Guo et $\mathrm{al}^{20}$ reported that the median serum VEGF level in the HCC patients $(285 \mathrm{pg} / \mathrm{mL})$ was significantly higher than that of healthy controls $(P=0.021)$, which also supports the results of Kamaiyama et al, ${ }^{21}$ Liovet et al, ${ }^{22}$ and Niizeki et al. ${ }^{23}$

Table I VEGF levels in patients (HCC, non-HCC) and control groups

\begin{tabular}{|c|c|c|c|c|}
\hline VEGF & HCC group & Non-HCC group & Control group & P-value \\
\hline Plasma VEGF, pg/mL Mean \pm SD & $488.46 \pm 139.07$ & $197.93 \pm 50.37$ & $134.13 \pm 5 \mid .9$ & $0.001 *$ \\
\hline Liver tissue VEGF Mean \pm SD & $1.92 \pm 0.6^{\mathrm{a}}$ & $0.62 \pm 0.28^{b}$ & - & $0.001 *$ \\
\hline
\end{tabular}

Notes: $P$, comparison of plasma VEGF levels between the control group and the HCC and non-HCC groups; and between HCC and non-HCC group. It also includes comparison of expression levels of liver tissue VEGF between $\mathrm{HCCl}$ and non- $\mathrm{HCCl}$ groups. Dash indicates no data, as the control group did not undergo liver biopsy. *Indicates statistically significant values. ${ }^{a}$ represents $(\mathrm{HCCl})$; brepresents non $(\mathrm{HCCl})$.

Abbreviations: VEGF, vascular endothelial growth factor; HCC, hepatocellular carcinoma; SD, standard deviation. 
Table 2 Correlation between plasma VEGF level and clinical, laboratory and imaging findings of the all HCC studied patients

\begin{tabular}{|c|c|c|c|c|c|c|c|c|c|c|c|c|}
\hline \multirow[t]{2}{*}{ Correlation } & \multicolumn{12}{|c|}{ Plasma VEGF } \\
\hline & $\begin{array}{l}\text { Age } \\
\text { (years) }\end{array}$ & $\begin{array}{l}\text { Number of } \\
\text { focal lesions }\end{array}$ & $\begin{array}{l}\text { Maximum focal } \\
\text { lesion size }\end{array}$ & $\begin{array}{l}\text { Child- } \\
\text { Pugh class }\end{array}$ & $\begin{array}{l}\text { MELD } \\
\text { score }\end{array}$ & $\begin{array}{l}\text { PV } \\
\text { thrombosis }\end{array}$ & ALT & AST & $\begin{array}{l}\text { Total } \\
\text { bil }\end{array}$ & S alb & INR & AFP \\
\hline $\begin{array}{l}\text { Pearson } \\
\text { correlation }(r)\end{array}$ & 0.378 & 0.683 & 0.101 & -0.061 & 0.202 & 0.266 & 0.113 & 0.259 & 0.181 & -0.204 & -0.017 & 0.398 \\
\hline$P$-value & $0.003 *$ & $0.001 *$ & 0.596 & 0.645 & 0.122 & $0.04 *$ & 0.389 & $0.045^{*}$ & 0.166 & 0.117 & 0.899 & $0.002^{*}$ \\
\hline
\end{tabular}

Note: *Significance level at $P<0.05$.

Abbreviations: VEGF, vascular endothelial growth factor; MELD, model for end-stage liver disease; PV, portal vein; ALT, alanine aminotransferase; AST, aspartate aminotransferase; bil, bilirubin; s alb, serum albumin; INR, international normalized ratio; AFP, alpha-fetoprotein; HCC, hepatocellular carcinoma.

In the present study, HCC tissue samples had significantly higher VEGF expression levels (1.915 \pm 0.604$)$ than did the non-HCC liver tissue samples in the non-HCC patients $(0.625 \pm 0.281)$. Kwon et $\mathrm{al}^{24}$ and Stroescu et $\mathrm{al}^{25}$ reported similar results. All these results demonstrate that angiogenesis drives the rearrangement of the hepatic architecture and leads to neoplastic transformation and that VEGF is a very important angiogenesis factor for HCC growth. ${ }^{26}$

The positive correlation between tissue and plasma VEGF levels suggests that the plasma VEGF level mirrors liver tissue expression. This finding suggests that plasma VEGF levels could be used to reflect liver tissue VEGF expression and HCC angiogenic activity, without performing invasive procedures for diagnosis. Obtaining plasma VEGF levels is an easy and simple procedure, which makes long-term monitoring of VEGF levels feasible, even after local intervention and therapies for HCC. Moreover, the absence of correlation between plasma VEGF levels on one hand and each of serum albumin, ALT levels, serum bilirubin, or INR among all the studied groups, suggests that VEGF reflects neither the hepatic synthetic functions nor inflammatory activity. This can exclude the possibility that the mere inflammatory process could have an influence on VEGF.

Plasma VEGF levels, in our study, were not significantly correlated with Child-Pugh class, MELD score, ALT levels, albumin and bilirubin levels, INR or Okuda stage in the HCC patients. The present results indicate that VEGF was

Table 3 Correlation between liver tissue VEGF and age, plasma VEGF level, AFP, Okuda stage, and MELD score among the $\mathrm{HCCl}$ patients

\begin{tabular}{llllll}
\hline Correlation & $\begin{array}{l}\text { Age } \\
\text { (years) }\end{array}$ & \multicolumn{4}{l}{ Liver tissue VEGF } \\
\cline { 3 - 6 } & $\begin{array}{l}\text { Plasma } \\
\text { VEGF }\end{array}$ & AFP & $\begin{array}{l}\text { Okuda } \\
\text { stage }\end{array}$ & $\begin{array}{l}\text { MELD } \\
\text { score }\end{array}$ \\
\hline $\begin{array}{l}\text { Pearson } \\
\text { correlation }(r)\end{array}$ & 0.726 & 0.962 & 0.323 & -0.208 & 0.486 \\
$P$-value & $0.001 *$ & $0.001 *$ & 0.082 & 0.457 & $0.006^{*}$ \\
\hline
\end{tabular}

Note: *Significance level at $P<0.05$.

Abbreviations: VEGF, vascular endothelial growth factor; AFP, alpha-fetoprotein; MELD, model for end-stage liver disease; HCC, hepatocellular carcinoma. positively correlated with patients' age, the number of HCC focal lesions, aspartate aminotransferase, AFP level, and presence of portal vein thrombosis. This in agreement with Sergio et al. ${ }^{27}$

In the present study, the plasma VEGF level was not significantly correlated with the size of HCC focal lesions. This in agreement with Li et al, ${ }^{28}$ Poon et al, ${ }^{29}$ and El-Houseini et al. ${ }^{30}$ However, Tseng et $\mathrm{al}^{31}$ and Sergio et $\mathrm{al}^{27}$ reported a significant positive correlation between plasma VEGF levels and the size of HCC focal lesions. In our study, the sample size was small and we assessed the correlation between plasma VEGF and the size of the largest focal lesion, not the sum of the focal lesions' sizes, which Tseng et $\mathrm{al}^{31}$ and Sergio et $\mathrm{al}^{27}$ assessed. Additionally, this variability in results could also be due to the different vascular growth patterns of HCC, as suggested by Jeng et al. ${ }^{32}$

Our results show that the plasma VEGF level was positively correlated with portal vein thrombosis, which is another determinant of tumor stage. ${ }^{29}$ This is in agreement

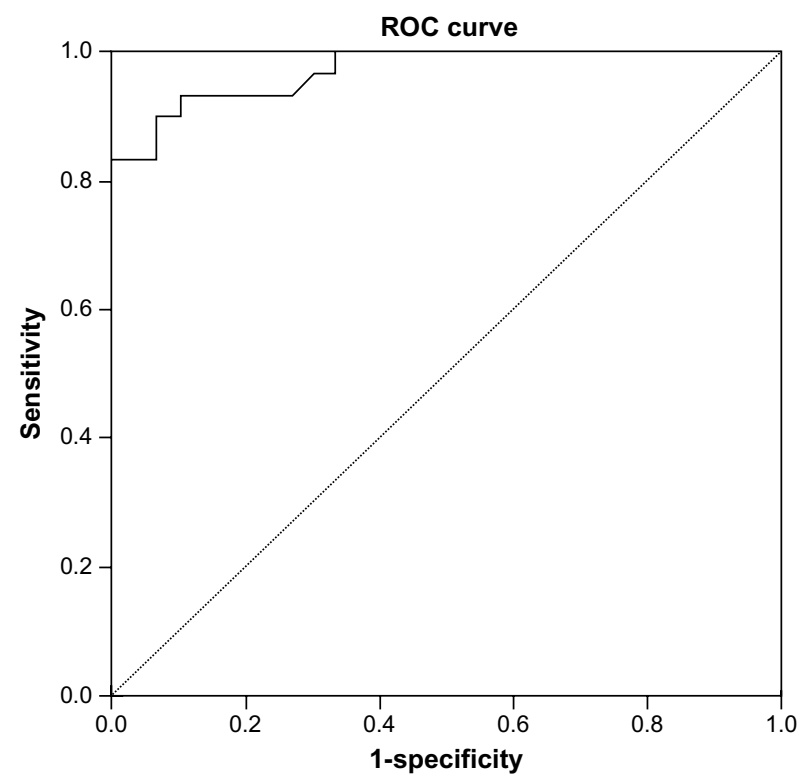

Figure I Receiver operating characteristic (ROC) curve showing the performance of plasma vascular endothelial growth factor for detecting hepatocellular carcinoma. 
with Poon et $\mathrm{al}^{29}$ and Sun et al. ${ }^{33}$ Sun et al showed that high expression of VEGF may reflect the vascular invasion of liver tumors. ${ }^{33}$ Yao et $\mathrm{al}^{34}$ studied the expression of VEGF and micro vessel density in the serum and liver tissues and their clinicopathologic features in HCC; they found that the serum VEGF levels in patients with portal vein emboli, metastasis, or a large HCC lesion $(>5 \mathrm{~cm})$ were significantly higher than in patients without portal vein emboli or metastasis, or those with small HCC lesions. In our study, the optimal cutoff value of plasma VEGF for diagnosing HCC was $271.85 \mathrm{pg} / \mathrm{mL}$ with a sensitivity of $90 \%$ and specificity of $90 \%$, an accuracy of $87.3 \%$, a positive predictive value of $92.3 \%$, and a negative predictive value of $88.1 \%$ (AUROC $=0.97$ ). When both AFP and VEGF levels were used to diagnose $\mathrm{HCC}$, the sensitivity and specificity for $\mathrm{HCC}$ detection were increased to $100 \%$ and $98.7 \%$, respectively, with an accuracy of $98.9 \%$. The simultaneous determination of both markers would improve the overall sensitivity for HCC detection. Our findings support the recommendations of El-Houseini et $\mathrm{al}^{30}$ and Mukozu et al. ${ }^{19}$ Also, this is in agreement, with El-mezayen and Darwish ${ }^{18}$ who generated a score incorporating both plasma VEGF and serum AFP beside other parameters for early detection of HCC.

In this work, we evaluated patients for both plasma and liver tissue VEGF. Their significant positive correlation could provide a noninvasive method for the diagnosis of HCC. Also, the significant correlation between plasma VEGF and the number of focal lesions and presence of portal vein thrombosis may indicate its value as a potential prognostic marker.

It is important to point out that our study has some limitations including the small number of patients and that longterm follow-up was not done and could be investigated in another study. Future studies incorporating plasma VEGF in the screening programs of HCC are warranted and may increase their sensitivity. However, standardization of the assay and the cut points will remain a challenge and therefore will benefit from large collaborative studies.

\section{Disclosure}

The authors report no conflicts of interest in this work.

\section{References}

1. Ferlay J, Shin H, Bray F, et al. Estimates of worldwide burden of cancer in 2008: GLOBOCAN 2008. Int J Cancer. 2010;127(12):2893-2917.

2. Jemal A, Bray F, Center M, et al. Global cancer statistics. CA Cancer J Clin. 2011;61:69-90.

3. Bartlett D, Carr B, Marsh J. Cancer of the liver. In: Devita VT, Hellman JS, Rosenberg S, editors. Cancer: Principles and Practice of Oncology. 7th ed. New York, NY: Lippincott Williams and Wilkins; 2005: 986-1008.
4. Masuzaki R, Karp S, Omata M. New serum markers of hepatocellular carcinoma. Semin Oncol. 2012;39:434-439.

5. Pybus O, Drummond A, Nakano T, et al. The epidemiology and iatrogenic transmission of hepatitis C virus in Egypt: a Bayesian coalescent approach. Mol Biol Evol. 2003;20(3):381-387.

6. International agency for research on cancer, WHO, Globocan 2012: estimated cancer incidence, mortality and prevalence worldwide 2012. Available from: http://globocan.iarc.fr/Pages/fact_sheets_population. aspx? country=818. Accessed December 28, 2015.

7. Asayama Y, Yoshimitsu K, Nishihara Y, et al. Arterial blood supply of hepatocellular carcinoma and histologic grading: Radiologic pathologic correlation. AJR Am J Roentgenol. 2008;190:W28-W34.

8. Kaseb A, Hanbali A, Cotant M, et al. Vascular endothelial growth factor in the management of hepatocellular carcinoma: a review of literature. Cancer. 2009;115(21):4895-4906.

9. Yamaguchi R, Yano H, Nakashima O, et al. Expression of vascular endothelial growth factor-C in human hepatocellular carcinoma. J Gastroenterol Hepatol. 2006;21:152-160.

10. Zhang Z, Liu Z, Sun Q. Expression of angiopoietins, Tie2 and vascular endothelial growth factor in angiogenesis and progression of hepatocellular carcinoma. World J Gastroenterol. 2006;12(26): $4241-4245$.

11. Abdel-Haleem H, El-Kateb S, Gohar N, Hamdy E. Evaluation of the diagnostic and prognostic value of AFP, PIVKA-II, VEGF and TGF- $\beta 1$ in the diagnosis and follow up of patients with hepatocellular carcinoma. Arab J Gastroenterol. 2007;8(3):84-89.

12. Yamaguchi R, Yano H, Nakashima Y, et al. Expression and localization of vascular endothelial growth factor receptors in human hepatocellular carcinoma and non-HCC tissues. Oncol Rep. 2000;7: 725-729.

13. He Y, Wang X, Gao S, et al. Ultrasound-guided fine needle biopsy of intrahepatic nodules and low elevation of AFP in early diagnosis of hepatocellular carcinoma. Hepatobiliary Pancreat Dis Int. 2005;4(1): $50-54$.

14. Ishii M, Gama H, Chida N, et al. Simultaneous measurements of serum alpha-fetoprotein and protein induced by vitamin $\mathrm{K}$ absence for detecting hepatocellular carcinoma. South Tohoku District Study Group. Am J Gastroenterol. 2000;95(4):1036-1040.

15. Pugh RN, Murray-Lyon IM, Dawson JL, Pietroni MC, Williams R. Transection of the oesophagus for bleeding oesophageal varices. $\mathrm{Br} J$ Surg. 1973;60(8):646-649.

16. Bedossa P, Poynard T. An algorithm for the grading of activity in chronic hepatitis C. The METAVIR Cooperative Study Group. Hepatology. 1996;24:289-293.

17. Wiesner R, Edwards E, Freeman R, et al. Model for end-stage liver disease (MELD) and allocation of donor livers. Gastroenterology. 2003;124:91-96

18. El-mezayen HA, Darwish H. Development of a novel score for early detection of hepatocellular carcinoma among high-risk hepatitis $\mathrm{C}$ virus patients. Tumour Biol. 2014;35(7):6501-6509.

19. Mukozu T, Nagai H, Matsui D, et al. Serum VEGF as a tumor marker in patients with HCV-related liver cirrhosis and hepatocellular carcinoma. Anticancer Res. 2013;33(3):1013-1021.

20. Guo J, Zhu X, Li X, Yang R. Impact of serum vascular endothelial growth factor on prognosis in patients with unresectable hepatocellular carcinoma after transarterial chemo-embolization. Chin J Cancer Res. 2012;24(1):36-43.

21. Kamaiyama T, Takahashi M, Nakanishi H, et al. $\alpha$ - fetoprotein, vascular endothelial growth factor receptor-1 and early recurrence of hepatoma. World J Gastroenterol. 2012;18(4):340-348.

22. Liovet J, Peña $\mathrm{C}$, Lathia $\mathrm{C}$, et al. Plasma biomarkers as predictors of outcome in patients with advanced hepatocellular carcinoma. Clin Cancer Res. 2012;18(8):2290-2300.

23. Niizeki T, Sumie S, Torimura T, et al. Serum vascular endothelial growth factor as a predictor of response and survival in patients with advanced hepatocellular carcinoma undergoing hepatic arterial infusion chemotherapy. J Gastroenterol. 2012;47(6):686-695. 
24. Kwon S, Jeong S, Jang J, et al. Cyclooxygenase-2 and vascular endothelial growth factor in chronic hepatitis, cirrhosis and hepatocellular carcinoma. Clin Mol Hepatol. 2012;18(3):287-294.

25. Stroescu C, Dragnea A, Ivanov B, et al. Expression of p53, Bcl-2, VEGF, Ki67 and PCNA and prognostic significance in hepatocellular carcinoma. J Gastrointestin Liver Dis. 2008;17(4):411-417.

26. An F, Matsuda M, Fujii H, Matsumoto Y. Expression of vascular endothelial growth factor in surgical specimens of hepatocellular carcinoma. J Cancer Res Clin Oncol. 2000;126:153-160.

27. Sergio A, CristoforiC, Cardin R, et al. Transcatheter arterial chemoembolization (TACE) in hepatocellular carcinoma (HCC): the role of angiogenesis and invasiveness. Am J Gastroenterol. 2008;103(4): 914-921.

28. Li X, Tang Z, Zhou G, et al. Significance of vascular endothelial growth factor mRNA expression in invasion and metastasis of hepatocellular carcinoma. J Exp Clin Cancer Res. 1998;17(1):13-17.

29. Poon R, Ng I, Lau C, et al. Serum vascular endothelial growth factor predicts venous invasion in hepatocellular carcinoma: a prospective study. Ann Surg. 2001;233(2):227-235.
30. El-Houseini M, Mohammed M, Elshemey W, et al. Enhanced detection of hepatocellular carcinoma. Cancer Control. 2005;12(4):248-253.

31. Tseng C, Lo H, Chen $\mathrm{P}$, et al. Clinical significance of plasma D-dimer levels and serum VEGF levels in patients with hepatocellular carcinoma. Hepatogastroenterology. 2004;51(59):1454-1458.

32. Jeng K, Sheen I, Wang Y, et al. Prognostic significance of preoperative circulating vascular endothelial growth factor mRNA expression in resectable hepatocellular carcinoma: A prospective study. World $J$ Gastroenterol. 2004;10:643-648.

33. Sun X, Wu Z, Liao X, et al. Tumor angiogenesis and its clinical significance in pediatric malignant liver tumor. World J Gastroenterol. 2005; 11(5):741-743.

34. Yao D, Wu X, Zhu Y, et al. Quantitative analysis of vascular endothelial growth factor, microvascular density and their clinicopathologic features in human hepatocellular carcinoma. Hepatobiliary Pancreat Dis Int. 2005;4(2):220-226.
Journal of Hepatocellular Carcinoma

\section{Publish your work in this journal}

The Journal of Hepatocellular Carcinoma is an international, peerreviewed, open access journal that offers a platform for the dissemination and study of clinical, translational and basic research findings in this rapidly developing field. Development in areas including, but not limited to, epidemiology, vaccination, hepatitis therapy, pathology and

\section{Dovepress}

molecular tumor classification and prognostication are all considered for publication. The manuscript management system is completely online and includes a very quick and fair peer-review system, which is all easy to use. Visit http://www.dovepress.com/testimonialsphp to read real quotes from published authors. 